\title{
Behenic Acid
}

National Cancer Institute

\section{Source}

National Cancer Institute. Behenic Acid. NCI Thesaurus. Code C68322.

A saturated very long-chain fatty acid with a 22-carbon backbone. Behenic acid is a major component of ben oil, extracted from the seeds of the moring a tree. 